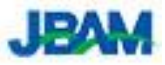

\title{
Blockchain Systems and Their Potential Impact on Business Processes
}

\author{
Stanton Heister \\ Portland State University \\ Vince LoRusso \\ TrueUp \\ Kristi Yuthas \\ Portland State University
}

\begin{abstract}
Blockchain technologies introduce fundamental changes in the mechanisms for verifying identity, transferring wealth, securing records, and tracing the movement of assets. The technology is poised to profoundly affect business processes and models in industry, government, and the social sector. Because graduating business students are likely to work in businesses that deploy or interact with blockchain and blockchain-related technologies, business programs must prepare them by introducing the intellectual foundations of this emerging technology and the operating practices it enables. This paper introduces a paper-based assignment designed to provide students this valuable opportunity.
\end{abstract}

Keywords: blockchain, business, students, teaching, technology

\section{Introduction}

Blockchain technology is essentially an advanced tracking system that links multiple parties involved in a business process - buyers, sellers, logistics companies, banks, and other intermediaries - in a single system known as a "distributed ledger." The transactions in this shared ledger are encrypted and immutable; this enables participants to establish a single source of truth, consensus around each transaction, and real-time tracking of assets and value between parties. Global investment in this groundbreaking technology by businesses and industries is increasing dramatically each year. Business students of today are likely to soon work in companies that deploy or interact with blockchain, so introducing them to these technologies is critical. Further, assurance of learning standards applied by the AACSB recognize the importance of equipping students with an understanding of emerging technologies (AACSB, 2019).

Despite businesses' rapidly growing investment in and experimentation with blockchain technology, many business school programs do not yet offer training in the subject. One reason for this may be the newness and technological complexity of the subject, which create a steep learning curve for professors who are seeking to cover it. In addition, formalized teaching 


\section{BLOCKCHAIN SYSTEMS AND BUSINESS PROCESSES}

materials on blockchain - in particular, hands-on assignments for beginning students without computer science backgrounds - are difficult to find.

This paper provides a simple pencil-and-paper assignment that can be used to introduce students to blockchain software from a user perspective. Most business users do not need to understand the mathematical and technological underpinnings of blockchain platforms to learn how these systems operate and to recognize their potential value for business. The hands-on project in this paper is designed to help students develop a working understanding of the basic concepts of this high-potential technology.

\section{Background}

Blockchain is positioned to bring major changes to all areas of business. Students graduating today need to understand what blockchain technology is and how it is likely to affect their future professions. Because blockchain has the potential to profoundly disrupt many industries, training students about it now and in the near future is increasingly important. The knowledge that business students gain from their basic accounting and information systems courses provides a solid foundation for understanding this technology.

Blockchain has captured the attention of companies across many vertical markets; governments; and venture capital firms. Investment in the technology is rapidly growing. International Data Corporation (IDC), a global provider of market intelligence, estimates that worldwide spending on blockchain solutions reached over $\$ 2$ billion in 2018, an increase of more than $100 \%$ over 2017 (Shirer \& Goepfert, 2018). Additionally, IDC predicts that blockchain spending will grow at a compound annual growth rate of $81.2 \%$ over the next few years, reaching $\$ 9.7$ billion in 2021 (Shirer \& Goepfert, 2018). Driving this growth in spending is an increasing awareness of blockchain technologies among senior executives around the globe. In a 2018 Deloitte survey of over 1000 senior executives (in companies of $\$ 500$ million or more), $84 \%$ of executives agreed with the statement that "blockchain technology is broadly scalable and will eventually achieve mainstream adoption" (Pawczuk, Massey, \& Schatsky, 2018). Consistent with this, a 2019 report by the identity management firm Okta found that 61 percent of large global companies (over $\$ 1$ billion in revenue) are investing in some form of blockchain technology (Okta | the digital enterprise report, 2019).

Business students can benefit from exposure to blockchain technology. As with many emerging technologies, much of the early work in blockchain involves engineers and IT departments learning how to build out infrastructure and test theoretical applications in alpha and beta environments. Deloitte reports that $55 \%$ of the activities in the blockchain space are currently being driven by the R\&D and IT functions within the organization; to date, only $39 \%$ is being driven by business departments (Pawczuk et al., 2018). But as the technology becomes more proven and scalable, businesspeople will need to direct its application to business problems and opportunity areas within the company. Kris Bennett, Chief Learning Officer at Blockchain Training Alliance, notes that "there is a tremendous opportunity for developers and engineers but there is even more opportunity for non-technical [business] people. The most important person on your team is not the 


\section{BLOCKCHAIN SYSTEMS AND BUSINESS PROCESSES}

developer or engineer but the [business] storyteller ( Blockchain training alliance live $Q$ $\&$ A volume 7,2019$)$. As blockchain use increases, business students and faculty will increasingly be expected to know this technology. The 2020 exposure draft for AACSB accreditation policies states that "all AACSB-accredited schools will be expected to have processes in place to ensure that both learners and faculty are competent with current and emerging technologies" (AACSB, 2018 p.10).

Blockchain technologies are driving changes to key areas of management and business in almost every industry vertical. Certain industries may face radical disruption; others will take advantage of emerging blockchain technologies to innovate, solve problems, and improve efficiencies.

Key use cases that are emerging from proof of concepts and going into production are changing the way companies are managed, including how they reconcile records with trading partners, track product histories, streamline payments and receivables, and increase the safety of food and pharmaceuticals though new methods of provenance. Walmart, for example, is requiring all of its suppliers of leafy vegetables to be blockchain-enabled by September 2019, so that it can more easily track and trace the products in its chain in the event of an E. coli or salmonella outbreak (Hyperledger, 2018). This blockchain solution is expected to reduce, from weeks to minutes, the time it takes to identify a lot of bacteria-affected produce, potentially saving time, money, and lives. In addition, IBM and the shipping company Maersk have teamed to create a blockchain solution called TradeLens. TradeLens streamlines document workflows by digitizing and storing them on an immutable ledger where all partners in the supply chain have visibility. The TradeLens process improvements reduce paperwork and improve supply chain efficiencies. Finally, the banking industry is using blockchain-related process changes to generate new efficiencies in many areas. In claims processing and dispute resolution, for example, a proof of concept resulted in a decrease in dispute-resolution time from over 40 to under 10 days, improving cash flow and profits (Jenkinson, 2018).

These changes in business processes directly affect the way we manage our respective business areas and underscore the importance of raising the collective awareness and skill level of our business students and professionals before blockchain becomes a wide-scale solution for businesses. Indeed, blockchain-related business skills are essential precursors to blockchain solutions, as business will eventually drive the wide-scale adoption of the solutions.

\section{Educational resources}

Faculty and students know disruptive changes are coming, and many are interested in learning about blockchain. Because the field is so new, blockchain-related educational resources have not yet been designed for university courses or with clear learning goals in mind. To date, there is a small number of professional articles and cases in reputable outlets, but no textbooks and few traditional resources that are suitable for classroom settings. This is not to say there is a lack of information on blockchain. Literally thousands of web articles, trade publications, and 


\section{BLOCKCHAIN SYSTEMS AND BUSINESS PROCESSES}

videos describe blockchain concepts. However, the quality of these resources varies greatly, and it is difficult to know which are accurate and reliable.

Professional services and business consulting firms have written high-quality white papers outlining blockchain concepts. Although some are excellent resources, they are often directed toward readers who already possess a foundational understanding of core concepts, or toward current or potential customers.

The most difficult resources to find are instructional materials for blockchain assignments and projects. A handful of blockchain activities and games are described online, but they typically explain only low-level technical concepts such as decentralized consensus or hashing algorithms - concepts that are more useful to students who are learning the underlying architecture than to ones who are approaching blockchains from a business user perspective. Likewise, there are online resources for interacting with blockchain software, but most are designed for software engineers and not business software users.

Being new and complex, blockchain concepts can be difficult to grasp through reading alone. Conceptual descriptions of blockchain technology and business use cases do not always give business students a line of sight into how businesses can apply these systems. The case described here enables students and faculty to engage blockchain and business software concepts through a hands-on, concrete approach.

\section{Business blockchain project}

The Smartify case, provided in full in the appendix, begins with a description of blockchain fundamentals that is written at a level appropriate for students with no prior knowledge of the technology. Some of the technical blockchain concepts, such as cryptography and consensus mechanisms, are complicated, but students do not need to master these concepts in order to understand what blockchains are and how businesses can use them. Business blockchains are essentially accounting ledgers that record transactions such as purchases, material transfers, and sales. The primary difference between blockchain and traditional enterprise systems is that blockchain systems can be shared by multiple companies, since the transactions are validated by all affected parties, secure, and unchangeable once they are recorded. This eliminates the need to reconcile different systems when questions arise about terms, activities, or payments between parties. These highly accurate shared ledgers allow businesses to transfer and track assets in new ways.

1. Transferring assets: blockchain enables unique identification of many assets, including ownership documents and cryptocurrency. This enables assets to be transferred directly between the parties, significantly reducing the need for intermediaries.

2. Tracking assets: blockchain can track the movement of ownership or an asset across multiple parties, such as through a supply chain, and make this movement visible to authorized parties. When each party benefits from transparency in this movement, the blockchain-enabled visibility reduces friction in the business process. 


\section{BLOCKCHAIN SYSTEMS AND BUSINESS PROCESSES}

Because the operation and value of shared ledgers can be difficult to grasp, we believe that working through this process step by step will benefit students.

The Smartify assignment helps students develop an in-depth understanding of how business blockchains work. It does so by providing:

1) A summary of blockchain basics

2) A discussion of software concepts relevant to business blockchains

3) A hands-on practice case in which students plan, record, and audit blockchain transactions.

4)

The assignment's description of a company and its practices helps students understand blockchain concepts in a business context. Using blockchain software in a pencil-and-paper format provides students with a concrete understanding of difficult concepts in an unintimidating setting.

When introduced through concrete examples, basic blockchain concepts are relatively easy for many business students to grasp, especially graduate students or undergraduate students who are in the upper division of their business programs or who have work experience. Business students tend to have a strong understanding of the concept of a transaction ledger, which, at its core, is very similar to a blockchain. They also understand the need for an audit trail - the need to track a transaction from an original source document to a database and ultimately to accounting reports. As a result, they can appreciate some of the key advantages of the blockchain system for business: accuracy, traceability, and security.

The Smartify case was developed by a company known as TrueUp, whose mission is to change the learning experience through interactive innovation challenges, technology simulations, and professional skill development using modes of gamification to engage learners differently. TrueUp developed the original version of the case as one of the exercises in its National Blockchain Challenge. Participants found the case to be very helpful in understanding how blockchain systems and software work. After completing the exercise, they were able to successfully execute transactions in an Oracle blockchain software environment and said the Smartify case made blockchain software seem more familiar and easier to grasp. In the final segment of the challenge, students were tasked with identifying potential errors and inefficiencies within another current business process, such as the sales or purchasing cycle. Their work on the Smartify assignment familiarized them with workflows and enabled them to understand ways blockchain could address problems and enhance the business cycle.

We have tested different versions of this case in our blockchain and analytics courses and have found that it helps students to more clearly picture business blockchains than they could from reading alone. Students also appreciated having the opportunity to learn about blockchain concepts. Many had heard about the technologies, but most did not understand them or how they could be implemented by businesses.

\section{Teaching notes}

The Smartify Blockchain assignment is appropriate for use in any undergraduate business major or graduate business program. The assignment does not assume that students have any 


\section{BLOCKCHAIN SYSTEMS AND BUSINESS PROCESSES}

prior blockchain knowledge and does not require access to a computer or software. Nor does the professor guiding the class need prior blockchain knowledge.

\section{Assignment Objectives}

The purpose of this project is to introduce students to blockchain concepts through a hands-on assignment that exemplifies how a blockchain system is operationalized in a common business setting. The objectives of the assignment are to:

- Introduce fundamental blockchain concepts

- Demonstrate the functioning of blockchain enterprise software

- $\quad$ Provide an opportunity to practice configuring an enterprise system

- $\quad$ Provide an opportunity to practice entering and evaluating business transactions

The Smartify assignment begins with a brief description of the fundamental elements of blockchain systems, followed by a discussion of how these elements differentiate blockchain enterprise software from traditional database-oriented systems. After reading the fundamentals, instructors may wish to provide opportunities for discussions of these concepts, either in class or online. Blockchain concepts are so deep and varied that no individual professor or blockchain practitioner can be an expert in all aspects. The goal here is to help students develop a working knowledge of the basic concepts.

We ask students to first read through the case, then have them work on the case together during class. The case is also appropriate as an independent homework assignment for in-person or online courses. Blockchain concepts can be overwhelming for some students. In our experience, even students who have read articles or watched videos on the topic often feel that it is too complex to master. The case is designed to help students realize that blockchains are similar to any other accounting ledger. After completing the case, they should feel confident in their understanding of the basic functioning of a blockchain.

Some instructors may wish to assign discussion questions in addition to the case. There are no "correct answers" to these questions. Rather, the questions will reinforce what students learned through the case and build on that knowledge through the process of speculation. With new blockchain innovations being announced every day, a discussion of the value of blockchain systems for businesses can be useful on its own.

\section{Additional materials and discussion questions}

The case is designed to be accessible to students with no prior knowledge of blockchain technology. If instructors would like to provide additional resources, many are available online. We have found Blockchain for Dummies, $2^{\text {nd }}$ IBM Limited Edition (Gupta, 2018) to be a great starting point for a business audience. The first two chapters of the book explain the business benefits and basic technical elements of blockchains. Many more resources, for both beginners and experts in blockchain, can be accessed through the Crypto Canon web resource page hosted by the venture capital firm Andreessen Horowitz. ). 


\section{BLOCKCHAIN SYSTEMS AND BUSINESS PROCESSES}

Some instructors may wish to assign discussion questions in order to build upon the foundational knowledge that students attain through the case study. Once students have a basic understanding of how blockchains function, they can benefit further by discussing what they have learned from the case and by speculating about the benefits of business blockchains for participating organizations. The following questions can be used to guide that discussion.

1) Describe the core elements of blockchain technology and enterprise blockchain software.

The information and definitions are presented at the beginning of the case, and the instructor can review them with the students. This can be done before or after students work through the case.

2) Does a shared blockchain system replace the existing enterprise systems of Smartify or its partners?

The blockchain supplements existing enterprise systems, but does not replace them. Even after a blockchain has been implemented, participants' enterprise systems will maintain records of their own internal transactions and transactions with external parties. A subset of these transactions will also be recorded on the blockchain. These are shared transactions, such as those depicted in the Smartify case.

3) How does the blockchain system depicted in the flowchart differ from traditional inventory management using an enterprise system?

A traditional enterprise system contains a broad variety of transactions for a single enterprise. The system is owned and controlled by that enterprise. In the Smartify case example, each of the customers and suppliers would have their own enterprise system and would record their own transactions. Companies sometimes allow their trading partners to see information like production or delivery schedules, but each company keeps its own record of transactions.

The blockchain system is shared between Smartify and its suppliers and customers. It does not replace the existing system but works in conjunction with it. Every node or partner keeps a complete record of transactions stored on the blockchain, and all parties can record transactions. When a transaction is recorded, it is validated by all participants, and the record is secured and unchangeable.

This eliminates many problems that result from erroneous or fraudulent transactions in an individual party's recordkeeping system. It is common for companies to have different records about their shared transactions, such as whether a product or payment was received. Because both parties validate transactions before they are stored, and because the records cannot be changed, many inconsistencies and disputes are avoided.

4) How is privacy maintained using the blockchain software? For example, how does Smartify ensure that customers don't see each other's orders and terms?

Participants in shared blockchain systems send information to one another through private channels. Only the parties who participate in a channel are allowed to view the information sent on it, unless they authorize other parties to view those transactions. 


\section{BLOCKCHAIN SYSTEMS AND BUSINESS PROCESSES}

Transactions on business blockchains are typically encrypted, so even though all partners store copies of the transactions, only the parties that have permission can read them.

5) What are the advantages of implementing a blockchain software package for inventory management?

a. $\quad$ Traceability - an authorized participant can track the movement of inventory throughout the entire inventory management system. As soon as a new transaction has been recorded and validated, that transaction will be visible across the network.

b. Dispute resolution - because both the partner transferring the asset and the partner receiving it agree upon and validate the transaction before it has been recorded to the blockchain, the number of disputes is minimized. Inventory transfer disputes typically arise from missing or improperly entered transactions or simple data entry errors, which cause discrepancies between the official records of the two parties. With blockchain, there is one shared copy of the transaction, so disputes can be easily resolved. The few errors that are missed by both parties during validation cannot be changed but can be resolved through additional transactions.

c. Auditing - because a company's suppliers and customers have already attested to the validity of transactions, these transactions are pre-audited. And because transactions cannot be changed once they have been recorded, their validity is also pre-established. This adds confidence to the audit process.

6) What are the advantages of using smart contracts/chaincode over traditional business documents?

This question was not addressed in the assignment, but it could be an interesting add-on for an instructor-guided discussion or for independent research by students. Because smart contracts are programmable, they can contain the types of if/then logic that are associated with a large number of traditional business documents and processes. This capability is especially powerful when information can be gathered from embedded chips, barcodes, or equipment. For example, a shipping notice with detailed tracking information could be instantly available to a customer and viewable in a block ledger as soon as a delivery truck leaves the warehouse. Because the smart contract and blockchain system are shared by Smartify and its customer, the smart contract could trigger actions in the ERP systems of both companies. Likewise, a delivery truck could automatically be summoned when a batch of goods leaves a production line or arrives on the supplier's shipping dock. The smart contract could release a payment for goods as soon as the goods arrive; chip readers in the manufacturer's loading dock or records from a bar code scanner could trigger the release. This feature will be especially valuable when companies are using cryptocurrencies for intercompany transactions. Some companies consider bitcoin and similar currencies to be too volatile for day-to-day transactions. However, these companies may be more amenable to "stable-coins," which are backed by US or foreign currency, and to other new solutions for reducing risk. 


\section{BLOCKCHAIN SYSTEMS AND BUSINESS PROCESSES}

\section{Conclusions}

Today's business students will graduate into a world in which blockchain plays an increasingly important role in business, government, and civil society. At a minimum, these students need a basic understanding of blockchain concepts, and confidence in their ability to learn and use blockchain systems. Because blockchain topics are so new, and because few business professionals have expertise in this area, even a small amount of blockchain training is valuable. Two students who had no prior knowledge of blockchain participated in the 2-weeklong National Blockchain Challenge, in which a version of this project appeared. Upon graduation, these students were hired by an accounting firm into roles that include designing blockchain workshops and educating senior managers on blockchain concepts.

The Smartify project presented here explains blockchain fundamentals, describes an inventory process in which blockchain software is used, and gives students experience in recording and validating blockchain transactions. This practical exercise can fill an important knowledge gap and give students the conceptual foundations and confidence to explore blockchain and other emerging technologies.

\section{References}

AACSB (2019). 2020 Standards for AACSB Business Accreditation, Exposure Draft 2. https://www.aacsb.edu//media/aacsb/docs/accreditation/business/standards-andtables/2020\%20aacsb\%20business $\% 20$ accreditation $\% 20$ standards $\% 20 \% 20$ exposure $\% 20$ draft\%20no\%201\%20distributefinal.ashx?la=en\&hash=E9B979E1F216730D3ABA637A A61CDEA29E7BB8CA

Blockchain Training Alliance (Producer) (2019, Jan 23, 2019). Blockchain training alliance live $\mathrm{Q} \&$ A volume 7. [Video/DVD] https://www.youtube.com/watch?v=0UZ2WVF6H3g

Chokshi, S., Dixon, C., Nazarov, D., Walden, J. \& Yahya, A. (2019). Crypto Cannon. https://a16z.com/2018/02/10/crypto-readings-resources/

Gupta, M. (2017). Blockchain for Dummies - IBM. Hoboken New Jersey: John Wiley \& Sons, Inc

Hyperledger (2018). How Walmart brought unprecedented transparency to the food supply chain https://www.hyperledger.org/resources/publications/walmart-case-study

IBM (2018, August 9). Maersk and IBM Introduce TradeLens Blockchain Shipping Solution. newsroom.ibm.com: https://newsroom.ibm.com/2018-08- 09-Maersk-and-IBMIntroduceTradeLens-Blockchain-Shipping-Solution.

Jenkinson, G. (Oct. 15, 2018). IBM's blockchain patents: From food-tracking and shipping to IoT and security solutions. https://cointelegraph.com/news/ibms-blockchain-patentsfrom-food-tracking-and-shipping-to-iot-and-security-solutions

Octa (2019) The digital enterprise report. https://www.okta.com/resources/whitepaper/thedigital-enterprise-report-how-the-worlds-largest-companies-are-evolving-withtechnology/

Pawczuk, M. \& Schatsky (2018). Deloitte's 2018 global blockchain survey. London, United Kingdom: Deloitte Consulting LLP. 
BLOCKCHAIN SYSTEMS AND BUSINESS PROCESSES

https://www2.deloitte.com/content/dam/Deloitte/cz/Documents/financial-services/cz2018-deloitte-global-blockchain-survey.pdf

Shirer, M., \& Goepfert, J. (2018, Jan 24, 2018). New IDC spending guide sees worldwide blockchain spending growing to $\$ 9.7$ billion in 2021 .

https://www.idc.com/getdoc.jsp?containerId=prUS43526618 


\section{BLOCKCHAIN SYSTEMS AND BUSINESS PROCESSES}

\section{Appendix}

\section{Business Partners on a Blockchain}

\section{Blockchain fundamentals}

At its core, blockchain technology is a distributed ledger system that allows two or more parties to store shared business transactions on a shared ledger. The well-known Bitcoin blockchain records transmission of cryptocurrency on its shared ledger. Businesses use blockchains to record all sorts of transactions, which may or may not involve cryptocurrency. Transactions stored on a shared ledger can be viewed by anyone who has been granted permission. Blockchains have several unique attributes that ensure that transactions are accurate, unchangeable, and secure:

- $\quad$ Blocks are groups of transactions, similar to a list of transactions on a Google sheet. Each list of transactions, or block, has a link to the block that came before it. Together the blocks form a "chain."

- $\quad$ Each block has an algorithmic hash - a unique code that is calculated based on the contents of the block-which can serve as an ID for that transaction. If even one character in the block is changed, the calculation will result in a completely different hash.

- $\quad$ There are multiple copies of each block of transactions, and the copies are regularly compared by the computers on which they are hosted to make sure they are identical. If a copy doesn't match up with the others, it is immediately apparent that transactions have been damaged or tampered with, and the copy is invalidated. This is the feature that makes transactions stored on the blockchain immutable.

- The transactions can be private. On a shared business blockchain, transactions are typically stored in encrypted format. Only authorized users with a key or password can view them.

\section{Smartify}

Smartify is a successful watch manufacturing company that takes standard watches and

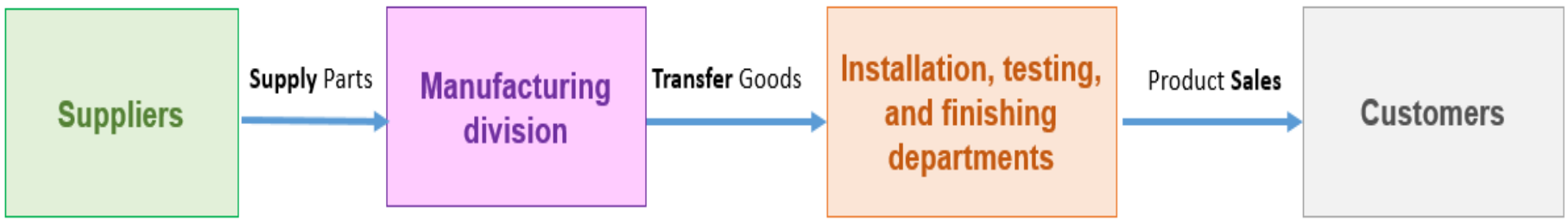

"smartifies" them by adding state-of-the art software and features.

The Smartify manufacturing process can be described as follows: 


\section{BLOCKCHAIN SYSTEMS AND BUSINESS PROCESSES}

Suppliers supply watch parts to Smartify's manufacturing division. After the watches are assembled, they are transferred through Smartify's installation, testing, and finishing departments. The finished products are then sold to customers. Smartify currently has three suppliers and three customers.

Smartify has strong relationships with its suppliers and customers, and the involved parties are working together to implement a shared blockchain. The new system will enable the parties to more effectively trace parts and products as they move through the manufacturing process, and will make inventory transfers between the parties more efficient.

\section{Blockchain Software}

Blockchain software is different from most traditional accounting and enterprise resource planning systems in that it is not owned by a single company. Ownership and management of the software is shared by all of the companies that use the system. Some basic terms associated with business blockchain software include:

- $\quad$ Node - a participant in transactions that will be recorded on the blockchain. In this assignment, each node is one department or company.

- Channel - a line of communication between two parties or nodes. Both parties agree to share a communication channel. Parties that share a channel validate every transaction before it is recorded in the ledger.

- $\quad$ Smart contract - a shared business document such as a purchase or material transfer that takes the form of programming code. These documents are considered "smart" because they can contain logic; for example a payment could automatically be released when an inventory barcode is scanned. Smart contracts can be thought of as self-executing, with terms of the agreement written into the code.

\section{Smartify Joins a Blockchain}

When blockchain software is introduced, new terminology and technology are associated with the manufacturing process. The new processes can be represented as follows:

Each of the boxes on the diagram (the three suppliers, four Smartify departments, and three customers) are represented in the software as peer nodes.

The peer nodes are connected by channels, represented by the arrows in the diagram. Every transaction recorded on the blockchain ledger must take place on one of these channels. The peer on the left side of the arrow is the initiator of the transaction, and the peer on the right side is the endorser of the transaction.

Every transaction between two peers is executed via smart contract. A smart contract is a computer program that takes the place of one or more traditional documents such as shipping notices and sales invoices. In the Smartify blockchain, there are three types of smart contracts: supply, transfer, and sales. 


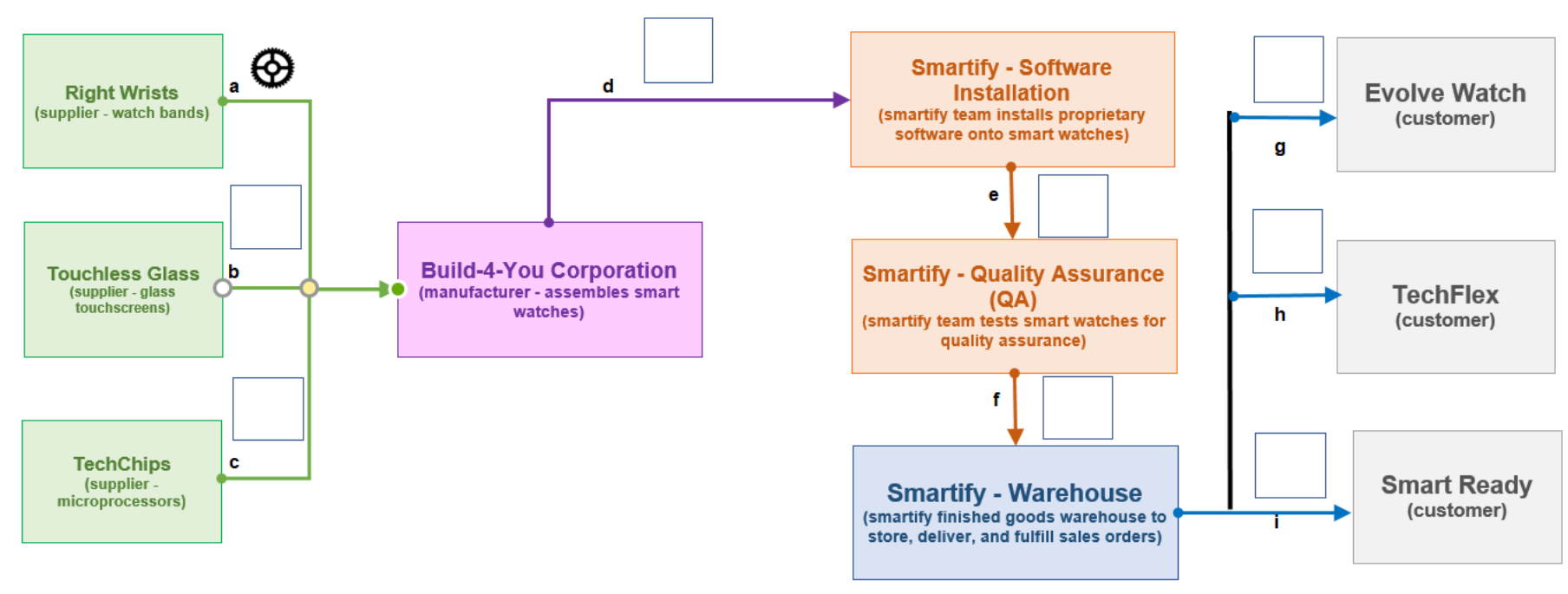

\begin{tabular}{|c|}
\hline Peer Nodes \\
\hline rightwrists \\
\hline touchlessglass \\
\hline techchips \\
\hline build4you \\
\hline installation \\
\hline qatesting \\
\hline warehouse \\
\hline evolvewatch \\
\hline techflex \\
\hline smartready \\
\hline
\end{tabular}

\begin{tabular}{|c|c|}
\hline & Channels \\
\hline a & supply-rightwrists \\
\hline b & supply-touchlessglass \\
\hline c & supply-techchips \\
\hline d & transfer-in-process \\
\hline e & transfer-testing \\
\hline f & transfer-finished-goods \\
\hline g & sales-evolvewatch \\
\hline h & sales-techflex \\
\hline i & sales-smartready \\
\hline
\end{tabular}

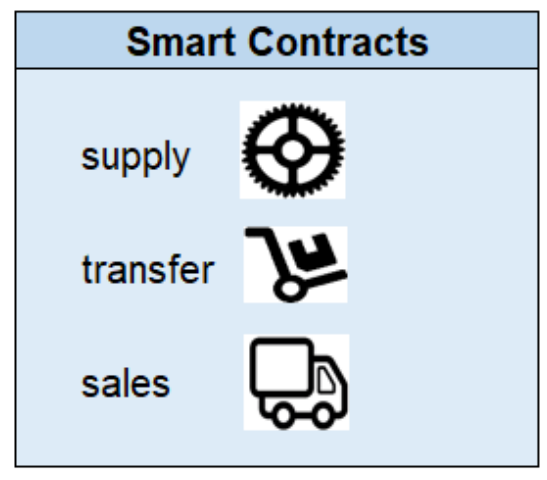

\section{Problems}

1) Each pair of partner nodes can execute a specific kind of smart contract. On this blockchain, partners can execute supply, transfer, or sales contracts. The gear icon next to arrow a indicates that the suppliers Right Wrists and Build4You can transact with each other using a supply smart contract. Fill in the small boxes on the diagram to indicate what kind of smart contract each pair of partners can execute.

2) Companies or departments that do business with each other establish channels on the blockchain. Once a channel is established, participants can execute smart contracts on the channel. Fill in the table below to show which peers transact across each channel, and which kind of contract is allowed on that channel. 


\section{BLOCKCHAIN SYSTEMS AND BUSINESS PROCESSES}

3) Companies or departments that do business with each other establish channels on the blockchain. Once a channel is established, participants can execute smart contracts on the channel. Fill in the table below to show which peers transact across each channel, and which kind of contract is allowed on that channel.

\begin{tabular}{|c|c|c|c|c|c|c|c|}
\hline & PEER NODE & & CHANNEL & & PEER NODE & & SMART CONTRACT \\
\hline a & rightwrists & is on... & suppply-rightwrists & with... & build4you & and uses... & supply \\
\hline$b$ & & is on... & & with... & & and uses... & \\
\hline $\mathrm{C}$ & & is on... & & with... & & and uses... & \\
\hline d & & is on... & & with... & & and uses... & \\
\hline e & & is on... & & with... & & and uses... & \\
\hline$f$ & & is on... & & with... & & and uses... & \\
\hline $\mathrm{g}$ & & is on... & & with... & & and uses... & \\
\hline $\mathrm{h}$ & & is on... & & with... & & and uses... & \\
\hline $\mathrm{i}$ & & is on... & & with... & & and uses... & \\
\hline
\end{tabular}

1) Supply: 600 wristbands were supplied by Right Wrists at $\$ 12.00$ price per unit, total $=\$ 7200$; hash c7fc 8866

2) Supply: 750 touch screens were supplied by Touchless Glass at $\$ 23.00$ price per unit, total $=\$ 17,250$; hash e67800ad

3) Supply: 800 microprocessors were supplied by TechChips at $\$ 7.50$ price per unit, total $=\$ 6,000$; hash $7688 \mathrm{~b} 6 \mathrm{ef}$

4) Sale: 250 smart watches were sold to Smart Ready, Inc at $\$ 160.00$ price per unit, total $=\$ 40,000$; hash $525 a 5962$

5) Sale: 100 smart watches were sold to Evolve Watch, Inc at $\$ 180.00$ price per unit, total $=\$ 18,000$; hash d008f7f8

6) Sale: 656 smart watches were sold to Techflex, Inc at $\$ 125.00$ price per unit, total $=\$ 82,000$; hash $=942 \mathrm{~b} 3582$

\begin{tabular}{|c|c|c|c|c|c|c|c|c|}
\hline \multicolumn{9}{|c|}{ Transaction ledger } \\
\hline & Initiator & Channel & Endorser & Smart contract & Price & Quantity & Amount & Hash \\
\hline 1) & rightwrists & supply-rightwrists & build4you & supply & $\$ 12.00$ & 600 & $\$ 7,200$ & $\mathrm{c} 7 \mathrm{fc} 8866$ \\
\hline 2) & & & & & & & & \\
\hline 3) & & & & & & & & \\
\hline 4) & & & & & & & & \\
\hline 5) & & & & & & & & \\
\hline 6) & & & & & & & & \\
\hline
\end{tabular}

${ }^{*}$ Shaded items are only visible to initiator and endorser.

\begin{tabular}{|c|}
\hline Peer Nodes \\
\hline rightwrists \\
\hline touchlessglass \\
\hline techchips \\
\hline build4you \\
\hline installation \\
\hline qatesting \\
\hline warehouse \\
\hline evolvewatch \\
\hline techflex \\
\hline smartready \\
\hline
\end{tabular}

\begin{tabular}{|c|c|}
\hline & Channels \\
\hline a & supply-rightwrists \\
\hline b & supply-techchips \\
\hline c & supply-touchlessglass \\
\hline d & transfer-in-process \\
\hline e & transfer-testing \\
\hline f & transfer-finished-goods \\
\hline g & sales-evolvewatch \\
\hline h & sales-techflex \\
\hline i & sales-smartready \\
\hline
\end{tabular}

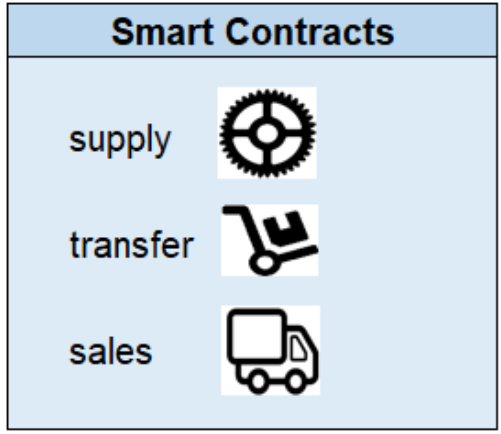

4) The list below shows examples of transactions between Smartify and its suppliers and customers on a single day. For each transaction listed below, make an entry in the 


\section{BLOCKCHAIN SYSTEMS AND BUSINESS PROCESSES}

transaction ledger. The peer node that sends inventory is the initiator, and the peer node that receives inventory is the endorser.

\begin{tabular}{|c|c|c|c|c|c|c|c|c|}
\hline \multicolumn{9}{|c|}{ Transaction ledger } \\
\hline & Initiator & Channel & Endorser & Smart contract & Price & Quantity & Amount & Hash \\
\hline 1) & rightwrists & supply-rightwrists & build4you & supply & $\$ 12.00$ & 600 & $\$ 7,200$ & c7fc8866 \\
\hline 2) & touchlessglass & supply-touchlessglass & build4you & supply & $\$ 23.00$ & 750 & $\$ 17,250$ & e67800ad \\
\hline 3) & techchips & supply-techchips & build4you & supply & $\$ 7.50$ & 800 & $\$ 6,000$ & $7688 \mathrm{~b} 6 \mathrm{ef}$ \\
\hline 4) & build4you & transfer-in-process & installation & supply & $\$ 50.00$ & 250 & $\$ 12,500$ & $460 \mathrm{dd} 865$ \\
\hline 5) & build4you & transfer-in-process & installation & transfer & $\$ 50.00$ & 100 & $\$ 5,000$ & ee954a27 \\
\hline 6) & build4you & transfer-in-process & installation & transfer & $\$ 50.00$ & 600 & $\$ 30,000$ & $36000 f 3 c 9$ \\
\hline 7) & installation & transfer-testing & qatesting & transfer & $\$ 75.00$ & 250 & $\$ 18,750$ & d4538ebb \\
\hline 8) & installation & transfer-testing & qatesting & transfer & $\$ 75.00$ & 100 & $\$ 7,500$ & $046 f 8$ ef63 \\
\hline 9) & installation & transfer-testing & qatesting & transfer & $\$ 75.00$ & 600 & $\$ 45,000$ & $8 d c 2 f 57 c$ \\
\hline 10) & qatesting & transfer-finished-goods & warehouse & transfer & $\$ 100.00$ & 250 & $\$ 25,000$ & 46b19d34 \\
\hline 11) & qatesting & transfer-finished-goods & warehouse & transfer & $\$ 100.00$ & 100 & $\$ 10,000$ & 49efde7bf \\
\hline 12) & qatesting & transfer-finished-goods & warehouse & transfer & $\$ 100.00$ & 600 & $\$ 60,000$ & $852495 d 2$ \\
\hline 13) & warehouse & sales-smartready & smartready & sales & $\$ 160.00$ & 250 & $\$ 40,000$ & $525 a 5962$ \\
\hline 14) & warehouse & sales-evolvewatch & evolvewatch & sales & $\$ 180.00$ & 100 & $\$ 18,000$ & d008f7f8 \\
\hline 15) & warehouse & sales-techflex & techflex & sales & $\$ 125.00$ & 656 & $\$ 82,000$ & $942 b 3582$ \\
\hline
\end{tabular}

*Shaded items are only visible to initiator and endorser.

5) Review the blockchain ledger below. Answer the following questions about the transactions stored in the ledger.

a. In which transaction were 250 watches sold to SmartReady? For how much were the watches sold?

b. In which transaction were 250 watches transferred from the installation department to quality assurance testing?

c. What was the value of the watches that were transferred?

d. How many microprocessors were purchased from Tech Chips? What was the amount paid for these supplies?

e. How many sales contracts were executed? What was the total amount of sales?

f. There is an error in transaction 4). What is it?

g. After correcting the error, what was the total amount of supplies purchased during the period? 


\section{Solutions}

1) Each pair of partner nodes can execute a specific kind of smart contract. On this blockchain, partners can execute supply, transfer, or sales contracts. The gear icon next to arrow a indicates that the suppliers Right Wrists and Build4You can transact with each other using a

\section{Smanctiny Indusstries, Lted}

\section{SMARTIFY INVENTORY WORKFLOW}

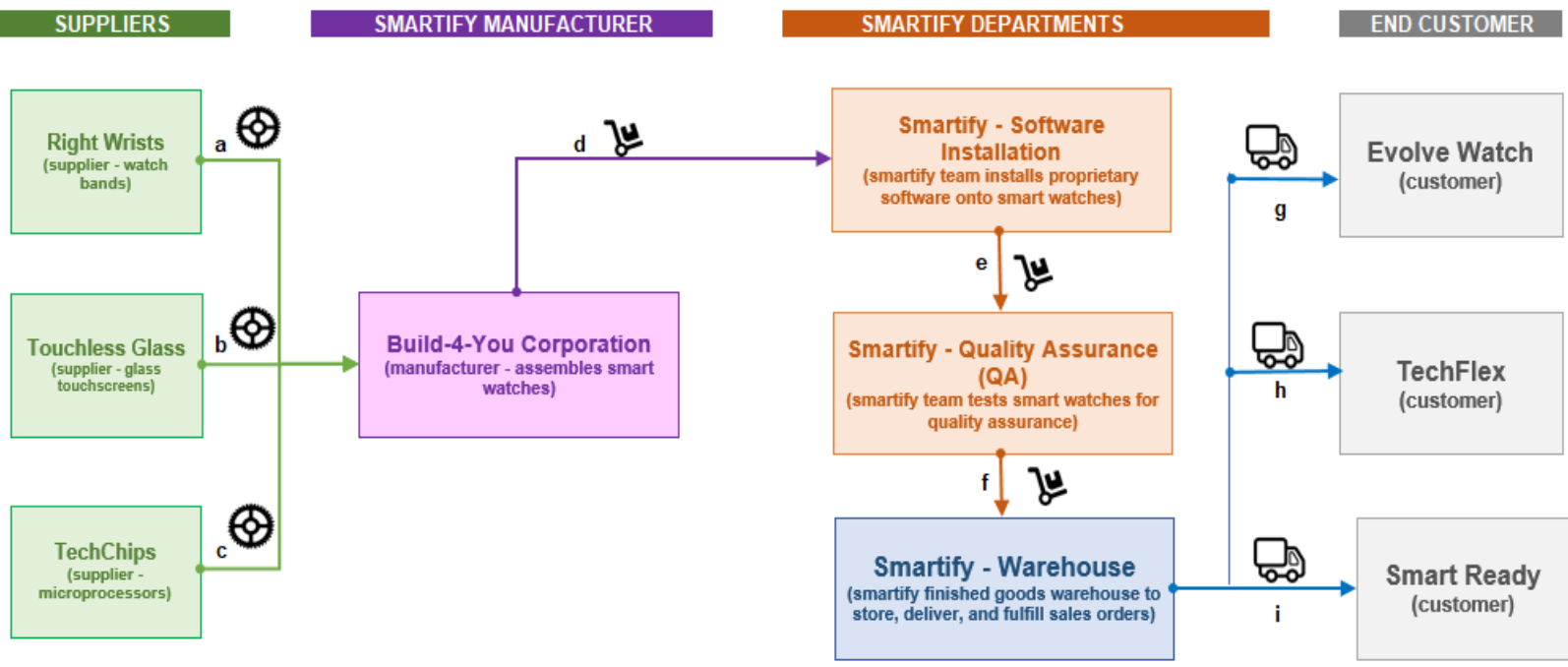

supply smart contract. Fill in the small boxes on the diagram to indicate what kind of smart contract each pair of partners can execute.

2) Companies or departments that do business with each other establish channels on the blockchain. Once a channel is established, participants can execute smart contracts on the channel. Fill in the table below to show which peers transact across each channel, and which kind of contract is allowed on that channel.

\begin{tabular}{|c|c|c|c|c|c|c|c|}
\hline & PEER NODE & & CHANNEL & & PEER NODE & & SMART CONTRACT \\
\hline a & rightwrists & is on... & suppply-rightwrists & with... & build4you & and uses... & supply \\
\hline $\mathrm{b}$ & touchlessglass & is on... & supplier-touchlessglass & with... & build4you & and uses... & supply \\
\hline $\mathrm{c}$ & techchips & is on... & supplier-techchips & with... & build4you & and uses... & supply \\
\hline $\mathrm{d}$ & build4you & is on... & transfer-in-process & with... & installation & and uses... & transfer \\
\hline $\mathrm{e}$ & installation & is on... & transfer-testing & with... & qatesting & and uses... & transfer \\
\hline $\mathrm{f}$ & qatesting & is on... & transfer-finished goods & with... & warehouse & and uses... & transfer \\
\hline $\mathrm{g}$ & warehouse & is on... & sales-evolvewatch & with... & evolvewatch & and uses... & sales \\
\hline $\mathrm{h}$ & warehouse & is on... & sales-techflex & with... & techflex & and uses... & sales \\
\hline $\mathrm{i}$ & warehouse & is on... & sales-smartready & with... & smartready & and uses... & sales \\
\hline
\end{tabular}




\section{BLOCKCHAIN SYSTEMS AND BUSINESS PROCESSES}

3) The list below shows examples of transactions between Smartify and its suppliers and customers on a single day. For each transaction, make an entry in the transaction ledger. The peer node that sends inventory is the initiator, and the peer node that receives inventory is the endorser.

1) Supply: 600 wristbands were supplied by Right Wrists at $\$ 12.00$ price per unit, total $=\$ 7200$; hash c7fc8866

2) Supply: 750 touch screens were supplied by Touchless Glass at $\$ 23.00$ price per unit, total $=\$ 17,250$; hash e67800ad

3) Supply: 800 microprocessors were supplied by TechChips at $\$ 7.50$ price per unit, total $=\$ 6,000$; hash $7688 \mathrm{~b} 6 \mathrm{ef}$

4) Sale: 250 smart watches were sold to Smart Ready, Inc at $\$ 160.00$ price per unit, total $=\$ 40,000$; hash $525 a 5962$

5) Sale: 100 smart watches were sold to Evolve Watch, Inc at $\$ 180.00$ price per unit, total $=\$ 18,000$; hash d008f7f8

6) Sale: 656 smart watches were sold to Techflex, Inc at $\$ 125.00$ price per unit, total $=\$ 82,000$; hash $=942 \mathrm{~b} 3582$

\begin{tabular}{|c|c|c|c|c|c|c|c|c|}
\hline \multicolumn{9}{|c|}{ Transaction ledger } \\
\hline & Initiator & Channel & Endorser & Smart contract & Price & Quantity & Amount & Hash \\
\hline 1) & rightwrists & supply-rightwrists & build4you & supply & $\$ 12.00$ & 600 & $\$ 7,200$ & $\mathrm{c} 7 \mathrm{fc} 8866$ \\
\hline 2) & touchlessglass & supply-touchlessglass & build4you & supply & $\$ 23.00$ & 750 & $\$ 17,250$ & e67800ad \\
\hline 3) & techchips & supply-techchips & build4you & supply & $\$ 7.50$ & 800 & $\$ 6,000$ & $7688 \mathrm{~b} 6 \mathrm{ef}$ \\
\hline 4) & warehouse & sales-smartready & smartready & sales & $\$ 160.00$ & 250 & $\$ 40,000$ & $525 a 5962$ \\
\hline 5) & warehouse & sales-evolvewatch & evolvewatch & sales & $\$ 180.00$ & 100 & $\$ 18,000$ & d008f7f8 \\
\hline
\end{tabular}

${ }^{\star}$ Shaded items are only visible to initiator and endorser.

4) Review the blockchain ledger below. Answer the following questions about

transactions stored in the ledger.

\begin{tabular}{|c|c|c|c|c|c|c|c|c|}
\hline \multicolumn{9}{|c|}{ Transaction ledger } \\
\hline & Initiator & Channel & Endorser & Smart contract & Price & Quantity & Amount & Hash \\
\hline 1) & rightwrists & supply-rightwrists & build4you & supply & $\$ 12.00$ & $\begin{array}{r}600 \\
\end{array}$ & $\$ 7,200$ & c7fc8866 \\
\hline 2) & touchlessglass & supply-touchlessglass & build4you & supply & $\$ 23.00$ & 750 & $\$ 17,250$ & e67800ad \\
\hline 3) & techchips & supply-techchips & build4you & supply & $\$ 7.50$ & 800 & $\$ 6,000$ & 7688b6ef \\
\hline 4) & build4you & transfer-in-process & installation & supply & $\$ 50.00$ & 250 & $\$ 12,500$ & $460 \mathrm{dd} 865$ \\
\hline 5) & build4you & transfer-in-process & installation & transfer & $\$ 50.00$ & 100 & $\$ 5,000$ & ee954a27 \\
\hline 6) & build4you & transfer-in-process & installation & transfer & $\$ 50.00$ & 600 & $\$ 30,000$ & $36000 f 3 c 9$ \\
\hline 7) & installation & transfer-testing & qatesting & transfer & $\$ 75.00$ & 250 & $\$ 18,750$ & d4538ebb \\
\hline 8) & installation & transfer-testing & qatesting & transfer & $\$ 75.00$ & 100 & $\$ 7,500$ & $046 f 8$ ef63 \\
\hline 9) & installation & transfer-testing & qatesting & transfer & $\$ 75.00$ & 600 & $\$ 45,000$ & $8 d c 2 f 57 c$ \\
\hline 10) & qatesting & transfer-finished-goods & warehouse & transfer & $\$ 100.00$ & 250 & $\$ 25,000$ & 46b19d34 \\
\hline 11) & qatesting & transfer-finished-goods & warehouse & transfer & $\$ 100.00$ & 100 & $\$ 10,000$ & 49efde7bf \\
\hline 12) & qatesting & transfer-finished-goods & warehouse & transfer & $\$ 100.00$ & 600 & $\$ 60,000$ & $852495 \mathrm{~d} 2$ \\
\hline 13) & warehouse & sales-smartready & smartready & sales & $\$ 160.00$ & 250 & $\$ 40,000$ & $525 a 5962$ \\
\hline 14) & warehouse & sales-evolvewatch & evolvewatch & sales & $\$ 180.00$ & 100 & $\$ 18,000$ & $d 008 f 7 f 8$ \\
\hline 15) & warehouse & sales-techflex & techflex & sales & $\$ 125.00$ & 656 & $\$ 82,000$ & $942 b 3582$ \\
\hline
\end{tabular}

*Shaded items are only visible to initiator and endorser. 


\section{BLOCKCHAIN SYSTEMS AND BUSINESS PROCESSES}

a. In which transaction were 250 watches sold to SmartReady? For how much were the watches sold? 13), $\$ 40,000$

b. In which transaction were 250 watches transferred from the installation department to quality assurance testing? What was the value of the watches that were transferred? 7), \$18,750

c. How many microprocessors were purchased from Tech Chips? What was the amount paid for these supplies?

$800, \$ 6,000$

d. How many sales contracts were executed? What was the total amount of sales?

Three: 13), 14), and 15), \$140,000

e. There is an error in transaction 4). What is it?

The smart contract that runs across this channel should be a transfer.

f. After correcting the error, what was the total amount of supplies purchased during the period?

$\mathbf{\$ 3 0 , 4 5 0}$, from transactions 1), 2), and 3) 